\title{
THE
}

\section{Sensory basis for detection of benthic prey in two Lake Malawi cichlids.}

Margot A. B. Schwalbe

Jacqueline F. Webb

University of Rhode Island, jacqueline_webb@uri.edu

Follow this and additional works at: https://digitalcommons.uri.edu/bio_facpubs

The University of Rhode Island Faculty have made this article openly available.

Please let us know how Open Access to this research benefits you.

This is a pre-publication author manuscript of the final, published article.

Terms of Use

This article is made available under the terms and conditions applicable towards Open Access Policy Articles, as set forth in our Terms of Use.

Citation/Publisher Attribution

Schwalbe, M. A.B., \& Webb, J. F. (2013). Sensory basis for detection of benthic prey in two Lake Malawi cichlids. Zoology, 117(2), 112-121.

Available at: http://dx.doi.org/10.1016/j.zool.2013.09.003

This Article is brought to you for free and open access by the Biological Sciences at DigitalCommons@URI. It has been accepted for inclusion in Biological Sciences Faculty Publications by an authorized administrator of DigitalCommons@URI. For more information, please contact digitalcommons-group@uri.edu. 
$5{ }^{1}$ Department of Biological Sciences, Center for Biotechnology and Life Sciences, University of 6 Rhode Island, 120 Flagg Road, Kingston, RI 02881

8 Corresponding Author: Margot A.B. Schwalbe, Department of Biological Sciences, Center for 9 Biotechnology and Life Sciences, University of Rhode Island, 120 Flagg Rd, Kingston, RI, 10 02881, mbergstrom@my.uri.edu.

11

12 Text pages: 32

13 Figures: 4 Table, 5 Figures (1 in color)

14

15 Key words: Aulonocara, Tramitichromis, lateral line, vision, multimodal, cobalt chloride 16 
17 Abstract

19 The adaptive radiations of African cichlids resulted in a diversity of feeding morphologies and 20 strategies, but the role of sensory biology in prey detection and feeding ecology remains largely

21 unexplored. Two endemic Lake Malawi cichlid genera, Tramitichromis and Aulonocara, feed on

22 benthic invertebrates, but differ in lateral line morphology (narrow and widened lateral line 23 canals, respectively) and foraging strategy. The hypothesis that they use their lateral line systems 24 differently was tested by looking at the relative contribution of the lateral line system and vision 25 in prey detection by Tramitichromis sp. and comparing results to those from a complementary 26 study using $A$. stuartgranti (Schwalbe et al., 2012). First, behavioral trials were used to assess the 27 ability of Tramitichromis sp. to detect live (mobile) and dead (immobile) benthic prey under 28 light and dark conditions. Second, trials were run before, immediately after, and several weeks 29 after chemical ablation of the lateral line system to determine its role in feeding behavior. Results 30 show that Tramitichromis is a visual predator that neither locates prey in the dark, nor depends 31 on lateral line input for prey detection and is thus distinct from A. stuartgranti, which uses its 32 lateral line or a combination of vision and lateral line to detect prey depending on light condition. 33 Investigating how functionally distinctive differences in sensory morphology are correlated with 34 feeding behavior in the laboratory and determining the role of sensory systems in feeding 35 ecology will provide insights into how sensory capabilities may contribute to trophic niche 36 segregation. 


\section{Introduction}

The mechanosensory lateral line system of fishes plays critical roles in prey detection,

41 predator avoidance, communication, rheotaxis, and navigation around obstacles (reviewed in

42 Webb et al., 2008; Bleckmann and Zelick, 2009). The system demonstrates a considerable

43 degree of morphological variation among bony fishes (Webb, 1989b), but understanding the

44 relationship between structure and function in the lateral line system and lateral-line mediated

45 behavior continues to be a particularly challenging task because of the multiple levels at which

46 both structure and function may vary.

The physiological response of the lateral line system (and ultimately behavior) depends

48 on the properties of the different morphological components that define the system. Variation in morphology of the neuromasts (hair cell morphology, density, and orientation, neuromast shape,

50 shape and length of the cupula into which the apical ciliary bundles of the hair cells are embedded, and patterns of neuromast innervation and central projections), and that of the lateral

52 line canals in which canal neuromasts are found (canal diameter, pore size, presence of canal

53 constrictions), and the hydrodynamic context (biotic, abiotic, and self-generated flows) in which

54 the system functions all contribute to physiological, and thus behavioral, responses. Ecological

55 correlates of lateral line morphology have been proposed (Dijkgraaf, 1963; reviewed by Webb,

56 1989b), but there are notable exceptions. For instance, fishes in hydrodynamically active

57 environments tend to have narrow canals and fewer superficial neuromasts, but this relationship

58 does not always hold in light of different sets of selection pressures (Carton and Mongtomery,

59 2004). In addition, some types of morphological variation (differences in canal diameter in the 60 vicinity of canal neuromasts) do not result in differences in physiological responses by 
neuromasts (Antarctic notothenioids, Coombs and Montgomery, 1992; Montgomery et al., 1994).

Testing hypotheses concerning the functional evolution of the lateral line system requires that experiments be carried out in a well-defined comparative context using closely-related species pairs with divergent morphology and the presentation of ecologically relevant stimuli. Narrow and widened cranial lateral line canals, two of the four types of lateral line canals defined among teleosts (Webb, 1989a), are of particular interest because of their distinctive morphologies and contrasting functional properties (theoretical and experimental work of Denton and Gray, 1988, 1989). Narrow canals are well-ossified with small canal pores and widened canals are typically weakly ossified with partial ossification of the canal roof over the canal neuromasts leaving large canal pores between neuromast positions that are covered by a tympanum-like epithelium typically pierced by very small pores. Narrow canals are widespread among teleosts, while widened canals have evolved convergently in just a dozen or so teleost families suggesting that the evolution of widened canals is adaptive, and further, that it represents an adaptation for prey detection.

The ability to determine the functional distinctions between narrow and widened canals has been hampered by the inability to identify appropriate species pairs that are accessible for experimental study. The percid fishes are a useful model system for illustrating the relationship between the functional morphology of the lateral line system and feeding ecology of fishes. European perch (Perca fluviatilis) and yellow perch (P. flavescens) have narrow canals and Eurasian ruffe (Gymnocephalus cernuus) has widened canals. The sensitivity of the large neuromasts in the widened canals of ruffe (van Netten, 2006) generally supports behavioral and ecological findings. European perch and ruffe have some seasonal and life stage-dependent diet 
84 overlap in their native habitat where they co-occur (Rezsu and Specziar, 2006; Schleuter and

85 Eckmann, 2008), but ruffe occupy a greater depth range than perch and spend more time close to

the substrate (Bergman, 1987, 1991). In addition, ruffe are able to feed more successfully in visually compromised habitats when compared to Perca spp. (Disler and Smirnov, 1977; Bergman, 1988; Janssen, 1997; Schleuter and Eckmann, 2006) and increase in abundance and replace perch in turbid water and/or low light conditions (Bergman, 1991). Interestingly, the accidental introduction of ruffe in the North American Great Lakes has generated concern over potential for competition with native yellow perch (P. flavescens, Ogle et al., 1995).

The speciose cichlids of the African Rift Lakes also provide opportunities for comparative studies of sensory biology, feeding behavior, and ecology. There has been intense study of the functional morphology of the cichlid feeding apparatus and the diverse trophic niches that they occupy (Fryer and Iles, 1972; Liem, 1973, 1980; Albertson et al., 2005; Hulsey et al., 2010), but only a few studies have addressed the sensory basis for prey detection (Hofman et al., 2009; O’Quin et al., 2010; Mogdans and Nauroth, 2011; Schwalbe et al., 2012). The vast majority of cichlid species have narrow cranial lateral line canals (e.g., Branson, 1961; Peters, 1973; Webb, 1989b). However, a few genera in Lake Tanganyika (Aulonocranus and Trematocara) and in Lake Malawi (Aulonocara, Alticorpus, and Trematocranus) and have widened canals (Konings, 2007).

One of these genera, Aulonocara (16-20 spp.), and a genus with narrow canals, Tramitichromis ( $\sim 6 \mathrm{spp}$. ), are found at either the rock-sand interface or over sand and feed on invertebrates buried in the sand (Fryer and Iles, 1972; Konings, 2007), but differ in prey search strategy. Tramitichromis plunges into the substrate filling their mouths with sand, and sift out invertebrate prey using their gill rakers ("sand sifting," Fryer, 1959). How they choose to direct 
107 their plunges, and thus the sensory basis for the detection of their benthic prey, is still unknown.

108 In contrast, $A$. stuartgranti swims just above the substrate, detect water flows generated by prey

109 with their lateral line system (as confirmed with cobalt chloride ablations), and strike at

110 individual prey in the sand (Konings, 2007; Schwalbe et al., 2012). With respect to lateral line

111 morphology, the narrow canals of Tramitichromis spp. are well-ossified with small pores while

112 the widened canals of Aulonocara spp. have large canal pores covered by an epithelium pierced

113 by small perforations. A recent analysis of neuromast morphology in juvenile Tramitichromis sp.

114 and A. stuartgranti (Becker, 2013; Becker et al., in prep.) has shown that these fishes have the

115 same number of canal neuromasts and canal pores, despite distinct differences in canal and pore

116 morphology (Fig. 1). They also have the same number of linear series or clusters of very small

117 superficial neuromasts on the head, but late stage juvenile (and presumably adult) A. stuartgranti

118 tend to have more superficial neuromasts within some of these series. The canal neuromasts are

119 diamond-shaped in both species, but those in A. stuartgranti are a bit larger (Fig. 1B) and tend to

120 sit in slight constrictions in the canal, which is a characteristic of many species with widened

121 canals.

Thus, Tramitichromis sp. and A. stuartgranti present an excellent model system in which

123 to ask questions about the relationship of lateral line morphology to its role in prey detection.

124 These fish differ with respect to only some aspects of the morphology of the lateral line system

125 (narrow versus widened canals, known to be functionally distinct in other taxa, and minor

126 differences in canal neuromast size [but not general shape], and the number of superficial

127 neuromasts). Experimental work has already determined that the lateral line system is critical for

128 prey detection in A. stuartgranti (Schwalbe et al., 2012) and it is hypothesized that the role of the

129 lateral line system in prey detection in Tramitichromis sp. would be different than in $A$. 
130 stuartgranti. In order to test this, behavioral trials (as in Schwalbe et al., 2012) were conducted in

131 the laboratory in which Tramitichromis sp. was presented with live (mobile) and dead

132 (immobile) prey (tethered adult brine shrimp) under light and dark conditions (Experiment I).

133 Then, the role of the lateral line system in prey detection was directly addressed by temporarily

134 inactivating the lateral line system with cobalt chloride (Experiment II). Data on number of prey

135 strikes, prey detection distance and angle and preference for live or dead prey was then compared 136 with that of $A$. stuartgranti (from Schwalbe et al., 2012) to contrast the roles of the lateral line 137 system and vision in prey detection behavior.

\section{Materials and methods}

Adult Tramitichromis sp. (= Tramitichromis for remainder of manuscript, unless

144 otherwise noted) were acquired from a commercial supplier (Old World Exotic Fish, Inc.,

145 Homestead, FL, USA) and housed in small groups in 190 L aquaria with mechanical and

146 biological filtration. For housing and experimental procedures, fish were maintained at 1 ppt salt

147 (Cichlid Lake Salt, Seachem Laboratories, Inc., Madison, GA, USA) at $26 \pm 1{ }^{\circ} \mathrm{C}$ with a $12: 12 \mathrm{hr}$

148 light:dark cycle. Fish were fed daily with cichlid pellets (New Life Spectrum Cichlid Formula;

149 New Life International, Inc., Homestead, FL, USA) and supplemented with live adult brine

150 shrimp. Animal care and all experimental procedures followed an approved University of Rhode

151 Island IACUC protocol. 


\subsection{Behavioral Trials}

Two experiments were conducted to determine the ability of Tramitichromis to detect live and dead prey in light and dark trials (Experiment I) and to determine the contribution of the lateral line system to prey detection in light trials (Experiment II).

\subsubsection{Experiment I - Light and Dark Trials}

Light and dark trials were conducted using Tramitichromis following Schwalbe et al.

(2012). Briefly, trials were performed in a large experimental tank (375 L) lined with sand. Adult brine shrimp (Artemia sp.) were tethered with elastic thread in pairs (1 live, 1 dead [freshly frozen]) onto each of six mesh platforms (a total of 6 live prey +6 dead prey $=12$ total prey) to serve as a proxy for naturally occurring benthic prey. Platforms were placed on the bottom of the tank in a $2 \times 3$ grid so that their top surfaces were flush with that of the sand. All filters in the experimental tank were turned off to eliminate hydrodynamic noise during all behavioral trials.

At the start of a trial, a fish was released from behind an opaque barrier into the experimental arena and recorded for 30 minutes using a HD digital video camera (Sony C HDRCX550V, 30 frames per second) mounted directly above the tank. Light trials were carried out under standard white fluorescent illumination and dark trials were conducted under infrared (IR) illumination (peak = 840 nm; Speco Provideo, IR-200/24, Amityville, NY, USA). Each of six naïve male fish (total length $[\mathrm{TL}]=99-110 \mathrm{~mm}$ ) was run sequentially through three light and then three dark trials for a total of 18 light trials and 18 dark trials. Each trial was performed on a different day, and trials were carried out over the course of five months with a mean time 
176 between the first light trial and last dark trial of 19 days for an individual fish. Several additional

177 light and dark trials were recorded in lateral view to observe the fishes' position relative to the 178 substrate.

\subsubsection{Experiment II - Chemical Ablation of the Lateral Line System}

181

182

183

184

185

186

187

188

189

190

191

192

193

194

195

196

197

198

In order to determine the role of the lateral line system in prey detection by

Tramitichromis, fish were treated with cobalt (II) chloride heptahydrate (cobalt chloride; SigmaAldrich, St Louis, MO, USA) to deactivate the lateral line system as in Schwalbe et al. (2012).

The results of Experiment I (above) demonstrated that while all fish were active during dark trials, the majority of fish did not feed in the dark so Experiment II consisted only of light trials. Each of three fish (all males, not used in Experiment I; TL $=92-98 \mathrm{~mm}$ ) was run through a sequence of three different trials. First, a 30 minute "pre-cobalt" trial (identical to the light trials in Experiment I) was carried out to establish a behavioral baseline. Two to three days later, the fish was treated in a large container filled with $0.1 \mathrm{mM}$ cobalt chloride in conditioned tap water for three hours (calcium $=60 \mathrm{mg} / \mathrm{L}$; Hach hardness test kit, Loveland, CO, USA) and returned to the experimental tank (calcium $=260 \mathrm{mg} / \mathrm{L})$. When the fish appeared to be behaving normally (e.g., normal respiration and swimming, about two hours after cobalt treatment), a "cobalt trial" was conducted. All fish resumed feeding on commercial pellets and/or live brine shrimp immediately following cobalt trials. After 21 days (in the experimental tank), the fish was run through a "post-cobalt" trial to assess recovery from cobalt treatment and allow a comparison with the "pre-cobalt" and "cobalt" trials. In a previous study (Schwalbe et al., 2012), the effect of handling was assess by running fish through one light and dark trial a few days before and 
199 immediately after a sham cobalt chloride treatment ( $=4$ trials/fish). For the sham treatment, fish

$200(n=2)$ were placed in a large container of conditioned tap water for three hours instead of the

201 cobalt chloride solution. Fish consumed prey during both light and dark trials before and after

202 sham treatment, so it appeared that handling had no effect on feeding behavior.

\subsection{Data analysis}

At the end of each trial, remaining prey were counted to determine the number and type of prey (live and dead) that had been consumed and strike success was also confirmed in video recordings. Video was analyzed using Premier Pro (Adobe, CS5) and images from video sequences of prey detections (e.g. when the fish oriented towards the prey) to prey strikes were exported for further analysis. These images were used to identify when detections occurred

211 relative to the start of the trial, during which phase of saltatory search strategy each prey was

212 detected (defined by O'Brien et al., 1989; a cycle of three swimming phases - caudal fin thrust, 213 glide and pause), and the order of prey strikes (live vs. dead) as an approximation of “prey 214 preference." In addition, detection distance and detection angle for each strike was measured 215 from the images using Image J (NIH, v. 1.41o).

All data were tested for normality (Kolmogorov-Smirnov test) and only detection

217 distance data needed to be $\log _{10}$ transformed to achieve normality. Separate tests using a

218 generalized linear mixed model (GLMM, SPSS, v.19) with pairwise post-hoc comparisons (least 219 significant differences, LSD) were used to detect differences in four variables (number of prey 220 strikes, detection distance, swimming phase in which strikes occurred, and order of prey capture) 221 with reference to prey type (live vs. dead) and light condition (light vs. dark). This approach 
222 allowed the selection of random (individual) and fixed effects (species, light condition, prey

223 type) while addressing repeated measures for the same individual. Prey preference was

224 calculated using a method described in Taplin (2007) in which prey preference was assessed by

225 ranking the prey according to the order in which they were consumed, and then calculating a

226 preference score by taking the mean of the order values for each prey type. Necessary

227 assumptions for this analysis were satisfied: multiple types of prey were offered simultaneously

228 (e.g. live and dead tethered brine shrimp) and prey consumed last could not be distinguished

229 from uneaten prey. Scores closer to one indicate a strong preference, whereas scores closer to

230 twelve (= total number of prey offered) indicate no preference or rejection. Preference scores for

231 live or dead prey in each light condition (light, dark) were compared using paired $t$-tests. Means

232 of prey preference scores from the three replicate trials carried out for each fish were calculated

233 prior to performing the paired $t$-test, so that the replicate variable was the fish (individual) and

234 not the trial. Finally, Watson's $U^{2}$-tests (Oriana, Kovach Computing Services, Anglesey, UK,

235 v.3) were used to analyze differences in detection angles with reference to prey type and light

236 condition. Differences were considered to be significant at the $P<0.05$ level for all statistical

237 tests. Values are given as mean \pm SE unless otherwise specified.

\section{3. Results}

Experiments I and II show that Tramitichromis is a visual predator that does not seek out

242 prey in the dark and does not depend on its lateral line system for detection of benthic

243 invertebrate prey in light trials. Tramitichromis is thus quite distinct from Aulonocara

244 stuartgranti, which relies on the interaction of vision and lateral line for prey detection and uses 
245 the lateral line system for detection of prey in the dark (Schwalbe et al. 2012).

246

247 248

249

250

251

252

253

254

255

256

257

258

259

260

261

262

263

264

265 $2665 \mathrm{~A})$.

267

\subsection{Experiment I-Light and Dark Trials}

Tramitichromis explored the tank by moving throughout the vertical extent of the water column. After the first prey detection, fish generally swam within $\sim 10 \mathrm{~cm}$ of the sand and struck at and removed prey from the platforms. Fish alternated between moving around the entire tank (vertically and horizontally) and swimming close to the sand, even after all 12 tethered brine shrimp were captured. Sand sifting was frequently observed during trials and after all prey were consumed.

In light trials, all Tramitichromis successfully struck at and consumed prey $(94.4 \%$ of total prey presented) but fish attacked more live prey than dead prey (LSD, $P=0.005$; Table 1 , Fig. 2A). Strikes on live prey preceded those on dead prey (paired $t$-test, $t_{5}=8.851, P<0.001$; Table 2) and live prey were detected at a greater distance than dead prey (live $=11.3 \pm 0.5 \mathrm{~cm}$, $\operatorname{dead}=9.0 \pm 0.5 \mathrm{~cm}$; LSD, $P=0.002$; Table 1 , Fig. $3 \mathrm{~A}$ ). Prey was detected non-uniformly around the fishes' bodies (Rayleigh test, $Z=107.98, P<0.001$; Fig. 4A) and all fish detected prey in the same relatively narrow range in front of the snout $\left( \pm 40^{\circ}\right.$ from body axis; Watson's $\mathrm{U}^{2}$-test, $P>0.05$ ). Tramitichromis swam close to the substrate (but higher above the substrate than A. stuartgranti) and demonstrated a saltatory search strategy (cyclic sequence of caudal fin thrust, glide, and pause). Prey was never detected during a caudal fin thrust, and more prey (live and dead prey combined) was detected during a pause $(77.3 \%)$ than during a glide $(22.7 \%$, Fig.

The results of dark trials were quite different. The median number of strikes was zero for 
268 both live and dead prey, which greatly contrasts with the median number of six strikes in light 269 trials (for live or dead prey offered; Fig. 2A). All fish actively swam around the tank in dark 270 trials as they did in light trials and some exhibited sand sifting behavior. A few strikes did occur

271 during dark trials, but one fish was responsible for 21 of the total 23 strikes (on 216 live and dead 272 prey presented in 18 trials). When comparing strikes on live and dead prey, no significant

273 differences were detected in any of the measured variables used to describe prey detection 274 behavior (e.g. prey preference, Table 2; number of prey strikes, Fig. 2A; detection distance, Fig. 275 3A; detection angle Fig. 4A; and swimming phase at prey detection, Fig. 5A), indicating that live 276 prey could not be distinguished from dead prey. However, when comparing the few strikes that did occur in dark trials $(n=23)$ to the 278 numerous strikes in light trials $(n=204$; Fig. 2A), significant differences were observed in some 279 aspects of behavior. In dark trials, prey were detected at a distance one fourth of that in light 280 trials (live and dead combined, light $=10.3 \pm 0.4 \mathrm{~cm}$, dark $=2.3 \pm 0.3 \mathrm{~cm} ; \mathrm{LSD}, P<0.001$; 281 Table 1, Fig. 3A) and more prey were detected during a glide in dark trials (60.9\% of strikes) 282 than in light trials $(22.7 \%$ of strikes; LSD, $P=0.002$, Table 1 , Fig. $5 \mathrm{~A})$. Even though prey were 283 detected in a wide range around the body during dark trials, the majority of prey were detected in 284 the same narrow range as in light trials $\left( \pm 40^{\circ}\right.$ from body axis, Watson's $\mathrm{U}^{2}$-test, $P>0.05$, Fig. 285 4A). While differences were observed in several behavioral parameters in light and dark trials, 286 Tramitichromis tended not to feed in the dark and when they did, prey appeared to be found 287 rather indiscriminately as fish explored the experimental arena.

\subsection{Experiment II - Chemical Ablation of the Lateral Line System}


Given the low number of strikes by Tramitichromis sp. in dark trials in Experiment I,

292

only light trials were carried out to determine the effects of lateral line ablation on their prey detection behavior.

The results for all trials - before (pre-cobalt trials), immediately following (cobalt trials), and three weeks after treatment with cobalt chloride (post-cobalt trials) - were comparable to results for light trials in Experiment I. All fish actively swam around the experimental arena and consumed the majority of live and dead prey presented in pre-cobalt $(66.7 \%$ of total prey presented), cobalt $(72.2 \%)$, and post-cobalt recovery $(88.9 \%)$ trials. The total number of strikes on live and dead prey was the same among the three trial types (GLMM, $P>0.05$; Table 3, Fig. 2B). Live and dead prey were detected from similar distances in all of these trials (Table 3; Fig. 3B). Prey were detected non-uniformly around the body in all trials (Rayleigh test, $P<0.04$; Fig. 4B) and detection angle did not vary with prey type or among sequential trials (Watson's $\mathrm{U}^{2}$-test, $P>0.05)$, like Experiment I light trials. In pre-cobalt trials, live prey were captured before dead prey (paired $t$-test, $t_{2}=8.66, P=0.013$ ), but this preference for live prey was absent in cobalt trials and post-cobalt trials $(P>0.05$; Table 2$)$. As in the light trials in Experiment I, most prey were detected during a pause, and the frequency of prey detection during a pause or glide did not differ among the pre-cobalt, cobalt, and post-cobalt trials (GLMM, $P>0.05$; Table 3, Fig. 5B).

\subsection{Comparison of feeding behavior in Tramitichromis and Aulonocara stuartgranti}

$$
\text { Interesting similarities and contrasts were found in prey detection behavior in }
$$

Tramitichromis sp. and Aulonocara stuartgranti. Both species swam around the tank in light and dark trials using a saltatory search strategy, but Tramitichromis tended to swim higher above the 
314 sand while searching for prey and pitched forward more (e.g. $\sim 45^{\circ}$ versus $\sim 30^{\circ}$ for $A$.

stuartgranti) during prey strikes. In addition, Tramitichromis did not demonstrate the swimming reversals (e.g. swam backwards) upon prey detection that $A$. stuartgranti did, and $A$. stuartgranti did not use the sand sifting strategy used by Tramitichromis.

In light trials, Tramitichromis and A. stuartgranti detected similarly high numbers of live and dead prey (GLMM, $P>0.05$, Table 4, Fig. 2A), and demonstrated a preference for live prey (Tramitichromis: paired $t$-test, $t_{5}=8.851, P<0.001, A$. stuartgranti: paired $t$-test, $t_{5}=5.551, P=$ 0.003; Table 2). In addition, both species detected more prey during a pause rather than during a glide, and did so with frequencies that were not statistically different (GLMM, $P>0.05$; Table 4, Fig. 5A). Interestingly, Tramitichromis detected live prey at longer distances than A. stuartgranti (LSD, $P=0.006$; Fig. 3A), but both species detected dead prey at distances that were not statistically different $(P>0.05)$. Detection angles were significantly different for Tramitichromis and A. stuartgranti (Watson $\mathrm{U}^{2}$-test, $U^{2}=0.468, P<0.001$; Fig. 4A); Tramitichromis detected the majority of prey in a narrower range of angles ( $\pm 40^{\circ}$ from body axis) than did $A$. stuartgranti $\left( \pm 90^{\circ}\right.$ from body axis).

In dark trials, Tramitichromis also demonstrated different prey detection behaviors than A. stuartgranti. Only half of the Tramitichromis ( $n=3$ of 6 fish) struck at prey while all $A$. stuartgranti ( $n=6$ fish) struck at prey. When prey was detected, Tramitichromis struck at fewer live prey than did $A$. stuartgranti (LSD, $P=0.006$ ), but the number of strikes on dead prey was not statistically different in the two species $(P>0.05$; Fig. 2A). Furthermore, although both species tended to detect more prey during a glide than during a pause in dark trials, Tramitichromis detected fewer prey during a glide than did A. stuartgranti (LSD, $P=0.020$; Fig. 5A). In addition, Tramitichromis detected prey at shorter distances than did A. stuartgranti (both 
337 prey types combined, LSD, $P<0.001$; Fig. 3A). Detection angles were not statistically different

338 in dark trials (Watson's $\mathrm{U}^{2}$-test, $P>0.05$ ) and both species found prey non-uniformly around 339 their bodies (Fig. 4A). The results suggest that Tramitichromis is a visual predator in contrast to 340 A. stuartgranti, which depends on lateral line input in prey detection, especially in the dark.

\section{Discussion}

The results of Experiments I and II showed that the combination of lateral line, olfactory, and tactile cues was not sufficient to elicit a prey strike response by Tramitichromis in the absence of visual cues, but that in light trials, a combination of sensory inputs may provide some

347 additional information when used in tandem with vision. This study has demonstrated that 348 closely related taxa that feed on the same prey in the same sensory environment, but have two 349 morphologically (and likely functionally) distinct lateral line systems, use different sensory systems to detect their prey under different light conditions in the laboratory.

\subsection{Feeding behavior of Tramitichromis} sensory cues were available to the fish allowing multimodal sensory input to be considered in the

356 interpretation of the results. In Experiment I light trials, all stimuli generated by the movement of 357 the brine shrimp were present and all sensory systems in Tramitichromis were intact (e.g. vision, 358 lateral line system, olfaction). In addition, the significance of prey movements for prey detection 359 - the visual motion stimulus, hydrodynamic flow, and spread of an odor plume generated by the 
motion of the brine shrimp - was addressed by providing both live and dead prey in all trials. Visual cues were absent in dark trials in Experiment I, but lateral line and olfactory systems were still intact (hydrodynamic and olfactory cues were available). In Experiment II (light trials only), the ability to detect hydrodynamic cues was eliminated by temporarily inactivating the lateral line system in cobalt trials, but visual and olfactory cues were still available. A dependence on more than one sensory modality was inferred when feeding behavior was not as robust in trials in which input to one or more sensory modalities was eliminated compared to trials in which all sensory systems were available.

Tramitichromis demonstrated the most robust feeding behavior when all sensory cues were available (Experiment I light trials). In these trials, Tramitichromis demonstrated a preference for live prey, which were detected from greater distances than were dead prey. The visual motion stimulus generated by live brine shrimp likely strengthened the visual stimulus necessary for prey detection and was responsible for the generation of robust prey detection behavior at longer distances. More prey detections occurred during a pause than a glide in light trials, when the prey could be localized in a more stable visual field. Even though the olfactory system was intact and olfactory cues were available during light and dark trials in Experiments I and II, behaviors characteristic of olfactory mediated prey detection (e.g. following and/or locating the source of an odor by zig-zagging through its odor plume, Hara, 1993) were not observed. These results all indicate that visual detection of prey is critical for feeding in Tramitichromis, and that they were relatively unsuccessful in detecting prey in dark trials likely because they could not see the prey. Finally, in Experiment II, feeding behavior was similar before, immediately following, and after the recovery from lateral line ablation using cobalt chloride, providing evidence that Tramitichromis does not appear to depend on its lateral line 
383 system for prey detection. Morphological confirmation of lateral line ablation by cobalt chloride was accomplished by fluorescently staining three juvenile Tramitichromis sp. with 4-Di-2-ASP $(63 \mu \mathrm{M}, 5 \mathrm{~min}$; also see Fig. 1) following a three hour treatment with either cobalt chloride in calcium free tank water $(0.1 \mathrm{mM})$, or in calcium free tank water (E. Becker, 2013). A lack of hair

387 cell staining in the central region of the neuromasts in Tramitichromis sp. was similar to that 388 observed in juvenile Aulonocara stuartgranti treated with cobalt chloride $(0.05$ and $0.1 \mathrm{mM}$, 389 Schwalbe et al, 2012).

Tramitichromis feeds on benthic invertebrates in the sand at the rock-sand interface in

391 Lake Malawi (Fryer, 1959; Koning, 2007), a community that is dominated by ostracods,

392 hydracarins, and chironomid larvae and also includes hydropsychid caddisfly, heptageneid

393 mayfly, and dryopoid beetle nymphs (Abdallah and Barton, 2003). Tramitichromis is known for 394 plunging into the sand, engulfing a mouthful of sand, and sifting it through their gill rakers, but 395 how they determine where to initiate this behavior is not known. Given the results of the current 396 study, it is likely that the fish can see minute changes in the substrate (e.g. a slightly exposed 397 invertebrate or movements by invertebrates in the substrate), perhaps in combination with 398 olfactory cues, to find these prey. Tactile cues may also elicit prey strikes and/or sand sifting 399 behavior, but lateral video recordings of behavioral trials suggest otherwise because 400 Tramitichromis swam several centimeters above the substrate and tended not to contact the 401 substrate with their pelvic fins.

402 Finally, the ability of one of the six Tramitichromis to detect both live and dead prey in 403 dark trials cannot be easily explained. Tramitichromis intermedius does have spectral sensitivity 404 peaks that are somewhat higher than other Lake Malawi cichlids examined (including $A$. 405 jacobfreibergi, Parry et al., 2005), but among all retinal cell types, the longest wavelength of 
maximum absorbance is only about $570 \mathrm{~nm}$ (for the double cones). However, two recent studies have demonstrated that cichlids show positive phototactic behavior (Oreochromis mossambicus, Shcherbakov et al., 2012) and strong foraging responses (Pelvicachromis taeniatus, Meuthen et al., 2012) in near-IR light. Thus, it is possible that this one Tramitichromis sp. was able to successfully detect prey in dark trials illuminated with a light source in the near IR range.

\subsection{Comparison of Prey Detection Behaviors in Two Benthic Feeding Cichlids}

This study has shown that Tramitichromis and A. stuartgranti use two distinct methods for detecting the same prey, likely due to the relative roles of their sensory systems. Both species exhibited a saltatory search strategy (which cycles between moving through an area and pausing to locate prey or reposition before the next forward movement) and different sensory systems are possibly important during a pause or glide in light and dark trials. Both Tramitichromis and $A$. stuartgranti appeared to visually scan for prey during a pause in light trials, when the visual field was stable. In light trials, Tramitichromis detected more prey in a narrow range of angles relative to the body axis suggesting that they may possess adequate binocular vision to localize prey (as shown in other teleosts, Sivak, 1978; Bianco et al., 2011; Miyazaki et al., 2011). In contrast, $A$. stuartgranti detected prey in a wider range of angles suggesting that binocular vision was not employed. However, they struck at a higher proportion of prey during a pause in light trials, suggesting that stabilization of the visual field favored successful prey detection. In dark trials, A. stuartgranti detected prey as swimming velocity decreased during a glide, allowing localization of prey as it came within the operational range of its lateral line system. The temporary ablation of the lateral line system with cobalt chloride had different 
429 effects on the two species. In Tramitichromis, prey detection behavior did not change with the

430 elimination of lateral line input, while for $A$. stuartgranti, there was a reduction in the number of

431 prey strikes in light trials and the complete elimination of prey detections in dark trials

432 (Schwalbe et al., 2012). It is concluded that Tramitichromis does not depend on lateral line input

433 for successful prey detection in contrast to A. stuartgranti, which depends on both vision and the

434 lateral line system in light trials, and uses its lateral line system to detect prey in the dark. The

435 correlation of this behavioral data with the difference in lateral line canal morphology in

436 Tramitichromis and A. stuartgranti suggest that the widened lateral line canals are an adaptation

437 for prey detection, especially in the absence of visual cues.

\subsection{Could sensory biology contribute to the feeding ecology of African cichlids?}

There has been a long history of discussion about the role of feeding mechanisms in the

442 definition of cichlid trophic niches (Fryer and Iles, 1972; Liem, 1973, 1980; McKaye and Marsh,

443 1983; Albertson et al., 2003) and the ways in which trophic niche differentiation and ecological

444 segregation occur among African cichlids (Goldschmidt et al., 1990; Reinthal, 1990; Sturmbauer

445 et al., 1992; Hori et al., 1993; Bouton et al., 1997; Genner et al., 1999a, b; Duponchelle et al.,

446 2005; Martin and Genner, 2009; Genner and Turner, 2012). In their landmark monograph, Fryer

447 and Iles (1972) reviewed the feeding biology and evolution of cichlid fishes of the African Rift

448 Lakes, but the ecological concepts of habitat partitioning and mechanisms underlying the

449 evolution of trophic diversity among cichlids has only been examined in detail more recently

450 (reviewed in Genner and Turner, 2005; Albertson, 2008). For instance, within the rock-dwelling

451 mbuna flock, it has been hypothesized that fine-scale niche partitioning occurs among species 
452 that forage on a combination of algae, aufwuchs, phytoplankton, and other seasonally available

453 food (Reinthal, 1990; Bouton et al., 1997; Genner et al., 1999b). However, there appears to be a

454 continuum in the degree of niche overlap among these species depending on whether or not

455 shared resources are limiting (Bouton et al., 1997; Genner et al., 1999b; Duponchelle et al., 456 2006), but a high degree of overlap may occur regardless of the availability of shared resources

457 (Martin and Genner, 2009).

Recent field observations by other investigators and results from the current study permit

459 some speculation about the sorts of behavioral and ecological interactions that may be occurring

460 between species of Tramitichromis and Aulonocara. A small number of stomach content

461 analyses show potential for diet overlap in these taxa (Fryer, 1959; Konings, 2007). Species of

462 Tramitichromis and Aulonocara have lake-wide distributions (Konings, 2007), presenting the

463 opportunity for spatial overlap. Where they co-occur, Aulonocara might experience interference

464 competition from Tramtichromis given its prey search strategies. For instance, members of these

465 two genera have been observed foraging in the same areas where Tramitichromis (and other sand

466 sifters) can interrupt foraging by Aulonocara (which hover just above the sand searching for

467 prey) by just swimming nearby (M. Kidd, personal communication). Furthermore, the sand

468 plunging behavior of Tramitichromis, removes and likely disrupts other invertebrates in the sand,

469 altering the topography of the bottom sediments, which may prevent Aulonocara from detecting

470 prey by swimming just above sand surface. These two taxa also occupy different depth ranges

471 (Tramitichromis spp.:<15 m, Konings, 2007; Aulonocara spp.: 5-120 m, Konings, 1990, 2007).

472 Species of Aulonocara may escape competition in shallower waters by foraging in deeper water.

473 Genner and Turner (2012) assigned several species of Aulonocara to an assemblage of "deep

474 benthic feeders" and suggested that these fishes have sensory adaptations (including 
475 modification of the cranial lateral line canal system) that should enable them to detect prey at the 476 depth at which they are found. This is supported by experimental work that demonstrated that $A$.

477 stuartgranti uses its lateral line system in prey detection, especially in the dark (Schwalbe et al., 478 2012). Furthermore, the ability of species of Aulonocara to detect prey non-visually may allow

479 them to forage crepuscularly and/or nocturnally (not yet documented in the field), thus

480 facilitating spatial and temporal segregation between Aulonocara species and other cichlids that 481 feed on benthic invertebrates in the sand, including species of Tramitichromis.

$482 \quad$ Future studies that involve the integration of the analysis of laboratory-based sensory 483 biology with field-based ecological studies will allow tests of hypotheses that: 1) evolutionary 484 changes in the morphology and physiological capabilities of a sensory system (such as widened 485 canals) are adaptations that allow species to occupy novel trophic niches, and 2) that species use 486 different combinations of sensory cues in the same sensory environment to spatially or 487 temporally partition similar resources in a common habitat.

489 Acknowledgements

490

491 We thank Emily Becker and Rebecca Scott who contributed Fig. 1A, B, and Douglas Moore 492 (Orthopedics Research Lab, Rhode Island Hospital) and Timothy Alberg, who generated and 493 analyzed $\mu \mathrm{CT}$ data in Fig. 1C, D. Dr. Nathan Bird provided comments that improved earlier 494 versions of the manuscript. Edward Baker (Facilities Manager, RI NSF EPSCoR Marine Life 495 Science Facility), Emily Becker, Joshua Hower, Brandon Fuller, Callie Veelenturf, and Rebecca 496 Scott were responsible for fish husbandry. This research was funded by the University of Rhode 497 Island College of the Environment and Life Sciences and the National Science Foundation (NSF) 
498 grant IOS 0843307 to JFW, and was supported in part by NSF EPSCoR Cooperative Agreement 499 EPS-1004057.

500 


\section{References}

Abdallah, A.M., Barton, D.R., 2003. Environmental factors controlling the distributions of benthic invertebrates on rocky shores of Lake Malawi, Africa. J. Great Lakes Res. 29, 202-215.

Albertson, R.C., 2008. Morphological diversity predicts habitat partitioning in a Lake Malawi cichlid species complex. Copeia 3, 689-698.

Albertson, R.C., Streelman, J.T., Kocher, T.D., 2003. Directional selection has shaped the oral jaws of Lake Malawi cichlid fishes. P. Natl. Acad. Sci-Biol. 100, 5252-5257.

Albertson, R.C., Streelman, J.T., Kocher, T.D., Yelick, P.C., 2005. Integration and evolution of the cichlid mandible: the molecular basis of alternate feeding strategies. PNAS 102, 16287-16292.

Becker, E.A., 2013. The distribution and ontogeny of neuromasts receptor organs and a comparison of methods for chemical ablation of the lateral line system in two cichlid fishes. Master's Thesis, University of Rhode Island.

Becker, E.A., Bird, N.C., Webb, J.F. Relationship of the distribution and ontogeny of neuromasts to the functional evolution of the lateral line system. In preparation.

Bergman, E., 1987. Temperature-dependent differences in foraging ability of two percids, Perca fluviatilis and Gymnocephalus cernuum. Environ. Biol. Fish. 19, 45-54.

Bergman, E., 1988. Foraging abilities and niche breadths of two percids, Perca fluviatilis and Gymnocephalus cernua, under different environmental conditions. J. Anim. Ecol. 57, 443-453.

Bergman, E., 1991. Changes in abundance of two percids, Perca fluciatilis and Gymnocephalus cernuus, along a productivity gradient: relations to feeding strategies and competitive 
abilities. Can. J. Fish. Aquat. Sci. 48, 536-545.

Bianco, I.H., Kampff, A.R., Engert, F., 2011. Prey capture behavior evoked by simple visual stimuli in larval zebrafish. Front Syst Neurosci. 5, 1-13.

Bleckmann, H., Zelick, R., 2009. Lateral line system of fish. Integr. Zool. 4, 13-25.

Bouton, N., Seehausen, O., van Alphe, J.J.M., 1997. Resource partitioning among rock-dwelling haplochromines (Pisces: Cichlidae) from Lake Victoria. Ecol. Freshw. Fish 6, 225-240.

Branson, B.A., 1961. The lateral-line system in the Rio Grande Perch, Cichlasoma cyanoguttatum (Baird and Girard). Amer. Midl. Nat. 65, 446-458.

Carton, A.G., Montgomery, J.C., 2004. A comparison of lateral line morphology of blue cod and torrentfish: two sandperches of the family Pinguipedidae. Env. Biol. Fish. 70, 123-131.

Coombs, S., Montgomery, J.C., 1992. Fibers innervating different parts of the lateral line system of an Antarctic notothenioid, Trematomus bernacchii, have similar frequency responses, despite large variation in the peripheral morphology. Brain Behav. Evol. 40, 217-233.

Denton, E.J., Gray, J.A.B., 1988. Mechanical factors in the excitation of the lateral lines of fish. In: Atema, J., Fay, R.R., Popper, A.N., Tavolga, W.N. (Eds.), Sensory Biology of Aquatic Animals. Springer-Verlag, New York, pp. 595-617.

Denton, E.J., Gray, J.A.B., 1989. Some observations on the forces acting on neuromasts in fish lateral line canals. In: Coombs, S., Gorner, P., Münz, H. (Eds.), The Mechanosensory Lateral Line: Neurobiology and Evolution. Springer-Verlag, New York, pp. 229-246.

Dijkgraaf, S. 1963. The functioning and significance of the lateral-line organs. Biol. Rev. 38, 51105.

Disler, N.N., Smirnov, S.A., 1977. Sensory organs of the lateral-line canal system in two percids and their importance in behavior. J. Fish. Res. Board Can. 34, 1492-1503. 
Duponchelle, F., Ribbink, A.J., Msukwa, A., Mafuka, J., Mandere, D., Bootsma, H., 2005. Food partitioning within the species-rich benthic fish community of Lake Malawi, East Africa. Can. J. Fish. Aquat. Sci. 62, 1651-1664.

Fryer, G., 1959. The trophic interrelationships and ecology of some littoral communities of Lake Nyasa with especial reference to the fishes, and a discussion of the evolution of a group of rock-frequenting Cichlidae. P. Zool. Soc. Lond. 132, 153-281.

Fryer, G., Iles, T.D., 1972. The cichlid fishes of the great lakes of Africa: their biology and evolution. Oliver and Boyd, Edinburgh.

Genner, M.J., Turner, G.F., 2005. The mbuna cichlids of Lake Malawi: a model for rapid speciation and adaptive radiation. Fish Fish. 6, 1-34.

Genner, M.J., Turner, G.F., 2012. Ancient hybridization and phenotypic novelty within Lake Malawi’s cichlid fish radiation. Mol. Biol. Evol. 29, 195-206.

Genner, M.J., Turner, Backer, S., Hawkins, S.J., 1999a. Niche segregation among Lake Malawi cichlid fishes? Evidence from stable isotope signatures. Ecol. Lett. 2, 185-190.

Genner, M.J., Turner, G.F., Hawkins, S.J., 1999b. Foraging of rocky habitat cichlid fishes in Lake Malawi: coexistence through niche partitioning? Oecologia 121, 283-292.

Goldschmidt, T., Witte, F., de Visser, J., 1990. Ecological segregation in zooplanktivorous haplochromine species (Pisces: Cichlidae) from Lake Victoria. Oikos 58, 343-355.

Hara, T., 1993. Role of olfaction in fish behavior. In: Pitcher, T.J. (Ed.), Behavior of Teleost Fishes, 2nd edn. Chapman and Hall, London, pp. 171-200.

Hofmann, C.M., O’Quin, K.E., Marshall, N.J., Cronin, T.W., Seehousen, O., Carleton, K.L., 2009. The eyes have it: regulatory and structural changes both underlie cichlid visual pigment diversity. PLoS Biol 7, e1000266. doi:10.1371/journal.pbio.1000266 
571 Hori, M., Gashagaza, M.M., Nshombo, M., Kawanabe, H., 1993. Littoral fish communities in

572

573

574

575

576

577

578

579

580

581

582

583

584

585

586

587

588

589

590

591

592

593

Lake Tanganyika: irreplaceable diversity supported by intricate interactions among species. Conserv. Biol. 7, 657-666.

Hulsey, C.D., Mims, M.C., Parnell, N.F., Streelman, J.T., 2010. Comparative rates of lower jaw diversification in cichlid adaptive radiations. J. Evolution. Biol. 23, 1456-1467.

Janssen, J., 1997. Comparison of response distance to prey via the lateral line in the ruffe and yellow perch. J. Fish Biol. 51, 921-930.

Konings, A., 1990. Koning's Book of Cichlids and Other Fishes of Lake Malawi. TFH

Publications Inc., Neptune City, New Jersey.

Konings, A., 2007. Malawi Cichlids in Their Natural Habitat, 4th edn. Cichlid Press, El Paso, Texas.

Liem, K.F., 1973. Evolutionary strategies and morphological innovations: cichlid pharyngeal jaws. Syst. Biol. 22, 423-441.

Liem, K.F., 1980. Adaptive significance of intra- and interspecific differences in the feeding repertoires of cichlid fishes. Am. Zool. 20, 295-314.

Martin, C.H., Genner, M.J., 2009. High niche overlap between two successfully coexisting pairs of Lake Malawi cichlid fishes. Can. J. Fish. Aquat. Sci. 66, 579-588.

McKay, K.R., Marsh, A., 1983. Food switching by two specialized algae-scraping cichlid fishes in Lake Malawi, Africa. Oecologia 56, 245-248.

Meuthen, D., Rick, I.P., Thünken, T., Baldauf, S.A., 2012. Visual prey detection by near-infrared cues in a fish. Naturwissenschaften 99, 1063-1066.

Miyazaki, T., Iwami, T., Meyer-Rochow, V.B., 2011. The position of the retinal area centralis changes with age in Champsocephalus gunnari (Channichthyidae), a predatory fish from 
coastal Antarctic waters. Polar Biol. 34, 1117-1123.

595

596

597

598

599

600

601

602

603

604

605

606

607

608

609

610

611

612

613

614

615

616

Mogdans, J., Nauroth, I.E., 2011. The Oscar, Astronotus ocellatus, detects and discriminates dipole stimuli with the lateral line system. J. Comp. Phys. A 197, 959-968.

Montgomery, J.C., Coombs, S., Janssen, J., 1994. Form and function relationships in lateral line systems: Comparative data from six species of Antarctic notothenioid fish. Brain Behav. Evol. 44, 299-306.

O’Brien, W.J., Evans, B.I., Browman, H.I., 1989. Flexible search tactics and efficient foraging in saltatory searching animals. Oecologica 80, 100-110.

O’Quin, K.E., Hofmann, C.M., Hofmann, H.A., Carleton, K.L., 2010. Parallel evolution of opsin gene expression in African cichlid fishes. Mol. Biol. Evol. 27, 2839-2854.

Ogle, D.H., Selgeby, J.H., Newman, R.M., Henry, M.G., 1995. Diet and feeding periodicity of ruffe in the St. Louis River Estuary, Lake Superior. T. Am. Fish. Soc. 124, 356-369.

Parry, J.W.L., Carleton, K.L., Spady, T., Carboo, A., Hunt, D.M., Bowmaker, J.K., 2005. Mix and match color vision: tuning spectral sensitivity by differential opsin gene expression in Lake Malawi cichlids. Curr. Biol. 15, 1734-1739.

Peters, H.M., 1973. Anatomie und Entwicklungsgeschichte des Laterallissystems von Tilapia 613 (Pisces, Cichlidae). Z. Morphol. Tiere. 74, 89-161.

Reinthal, P.N., 1990. The feeding habits of a group of herbivorous rock-dwelling cichlid fishes (Cichlidae: Perciformes) from Lake Malawi, Africa. Environ. Biol. Fish. 27, 215-233.

Rezsu, E., Specziar, A., 2006. Ontogenetic diet profiles and size-dependent diet partitioning of ruffe Gymnocephalus cernuus, perch Perca fluviatilis and pumpkinseed Lepomis gibbosus in Lake Balaton. Ecol. Freshw. Fish 15, 339-349.

Schleuter, D., Eckmann, R., 2006. Competition between perch (Perca fluviatilis) and ruffe 
(Gymnocephalus cernuus): the advantage of turning night into day. Freshwater Biol. 51, 287-297.

Schleuter, D., Eckmann, R., 2008. Generalist versus specialist: the performances of perch and ruffe in a lake of low productivity. Ecol. Freshw. Fish 17, 86-99.

Schwalbe, M.A.B., Bassett, D.K., Webb, J.F., 2012. Feeding in the dark: lateral-line-mediated prey detection in the peacock cichlid Aulonocara stuartgranti. J. Exp. Biol. 215, 20602071.

Shcherbakov, D., Knörzer, A., Hilbig, R., Haas, U., Blum, M., 2012. Near-infrared orientation of Mozambique tilapia Oreochromis mossambicus. Zoology 115, 233-238.

Sivak, J.G., 1978. The functional significance of the aphakic space of the fish eye. Can. J. Zool. $56,513-516$.

Sturmbauer, C., Mark, W., Dallinger, R., 1992. Ecophysiology of Aufwuchs-eating cichlids in Lake Tanganyika: niche separation by trophic specialization. Environ. Biol. Fish. 35, 283-290.

Taplin, R.H., 2007. Experimental design and analysis to investigate predator preferences for prey. J. Exp. Mar. Biol. Ecol. 344, 116-122.

van Netten, S.M., 2006. Hydrodynamic detection by cupulae in a lateral line canal: functional relations between physics and physiology. Biol. Cybern 94, 67-85.

Webb, J.F., 1989a. Gross morphology and evolution of the mechanosensory lateral line system in teleost fishes. Brain Behav. Evolut. 33, 34-53.

Webb, J.F., 1989b. Neuromast morphology and lateral line trunk canal ontogeny in two species of cichlids: An SEM study. J. Morph. 202, 53-68.

Webb, J.F., Montgomery, J.C., Mogdans, J., 2008. Bioacoustics and the lateral line system of 
640

641

642

643

644 fishes. In: Webb, J.F., Fay, R.R., Popper, A.N. (Eds.), Fish Bioacoustics. SpringerVerlag, New York, pp. 145-182.

Webb, J.F. 2013. Morphological diversity, development, and evolution of the mechanosensory lateral line system. In: Coombs, S., Bleckmann, H. (Eds.), The Lateral Line System. Springer-Verlag, New York. 
Table 1. Generalized linear mixed model (GLMM) results for Tramitichromis feeding on live and dead prey during light and dark

646 trials (Experiment I) comparing number of prey strikes, detection distance, and swimming phase during prey detection (pause vs. 647 glide).

648

\begin{tabular}{|c|c|c|c|c|c|c|c|c|c|}
\hline \multirow[b]{2}{*}{ Source } & \multicolumn{3}{|c|}{ Number of Prey Strikes } & \multicolumn{3}{|c|}{ Detection Distance } & \multicolumn{3}{|c|}{ Pause vs. Glide } \\
\hline & $F$ & d.f. & $P$ & $F$ & d.f. & $P$ & $F$ & d.f. & $P$ \\
\hline Light/Dark & 273.28 & 1,68 & $<0.001$ & 40.89 & 1,213 & $<0.001$ & 10.39 & 1,213 & 0.001 \\
\hline Prey & 3.83 & 1,68 & n.s. & 2.52 & 1,213 & n.s. & 1.29 & 1,213 & n.s. \\
\hline Light/Dark $\times$ Prey & 4.68 & 1,68 & 0.034 & 0.25 & 1,213 & n.s. & 0.003 & 1,213 & n.s. \\
\hline
\end{tabular}


651 Table 2. Mean prey preference scores for Tramitichromis (Experiments I and II) and A.

652 stuartgranti (Experiment I only, data from Schwalbe et al., 2012) feeding on live and dead prey

653 in light and dark (Experiment I only) trials following Taplin (2007).

\begin{tabular}{|c|c|c|c|c|c|c|}
\hline & & & \multicolumn{2}{|c|}{ Light Trials } & \multicolumn{2}{|c|}{ Dark Trials } \\
\hline Species & Experiment & & Live & Dead & Live & Dead \\
\hline Tramitichromis & & & $5.74 * * *$ & 7.26 & 6.54 & 6.46 \\
\hline \multirow{3}{*}{$\begin{array}{l}\text { Aulonocara } \\
\text { stuartgranti }\end{array}$} & Experiment I & & & & & \\
\hline & & & & & & \\
\hline & & Pre-Cobalt & $5.25 *$ & 7.75 & & \\
\hline \multirow[t]{2}{*}{ Tramitichromis } & Experiment II & Cobalt & 6.08 & 6.92 & & \\
\hline & & Post-Cobalt & 6.67 & 6.33 & & \\
\hline
\end{tabular}

654

655 If the fish demonstrated a preference for a type of prey (indicated by a significant lower

656 preference score), it was always for live prey (paired $t$ - test, ${ }^{*} P<0.05$, ${ }^{* *} P<0.01,{ }^{* * *} P<0.001$ ). 
Table 3. Generalized linear mixed model (GLMM) results for Tramitichromis feeding on live and dead prey during light trials after

659 cobalt chloride treatment (Experiment II) comparing number of prey strikes, detection distance, and swimming phase during prey 660 detection (pause vs. glide).

661

\begin{tabular}{|c|c|c|c|c|c|c|c|c|c|}
\hline \multirow[b]{2}{*}{ Source } & \multicolumn{3}{|c|}{ Number of Prey Strikes } & \multicolumn{3}{|c|}{ Detection Distance } & \multicolumn{3}{|c|}{ Pause vs. Glide } \\
\hline & $F$ & d.f. & $P$ & $F$ & d.f. & $P$ & $F$ & d.f. & $P$ \\
\hline Trial & 1.38 & 2,12 & n.s. & 2.24 & 2,76 & n.s. & 0.000 & 2,75 & n.s. \\
\hline Prey & 2.87 & 1,12 & n.s. & 0.07 & 1,76 & n.s. & 0.001 & 1,75 & n.s. \\
\hline Trial $\times$ Prey & 0.96 & 2,12 & n.s. & 1.95 & 2,76 & n.s. & 0.000 & 2,75 & n.s. \\
\hline
\end{tabular}


Table 4. Generalized linear mixed model (GLMM) results for Tramitichromis (this study) and A. stuartgranti (data from Schwalbe et al., 2012) feeding on live and dead prey during light and dark trials (Experiment I) comparing number of prey strikes, detection distance, and swimming phase during prey detection (pause vs. glide).

\begin{tabular}{|c|c|c|c|c|c|c|c|c|c|}
\hline \multirow[b]{2}{*}{ Source } & \multicolumn{3}{|c|}{ Number of Prey Strikes } & \multicolumn{3}{|c|}{ Detection Distance } & \multicolumn{3}{|c|}{ Pause vs. Glide } \\
\hline & $F$ & d.f. & $P$ & $F$ & d.f. & $P$ & $F$ & d.f. & $P$ \\
\hline Species & 0.38 & 1,136 & n.s. & 2.34 & 1,444 & n.s. & 0.000 & 1,432 & n.s. \\
\hline Light/Dark & 352.89 & 1,136 & $<0.001$ & 156.46 & 1,444 & $<0.001$ & 0.000 & 1,432 & n.s. \\
\hline Prey & 12.46 & 1,136 & 0.001 & 6.24 & 1,444 & 0.013 & 0.003 & 1,432 & n.s. \\
\hline Light/Dark $\times$ Prey & 0.40 & 1,136 & n.s. & 0.12 & 1,444 & n.s. & 0.000 & 1,432 & n.s. \\
\hline Species $\times$ Light $/$ Dark & 7.69 & 1,136 & 0.006 & 23.17 & 1,444 & $<0.001$ & 0.000 & 1,432 & n.s. \\
\hline Species $\times$ Prey & 1.29 & 1,136 & n.s. & 4.45 & 1,444 & 0.036 & 0.003 & 1,432 & n.s. \\
\hline Species $\times$ Light $/$ Dark $\times$ Prey & 4.07 & 1,136 & 0.046 & 2.11 & 1,444 & n.s. & 0.000 & 1,432 & n.s. \\
\hline
\end{tabular}




\section{Figure Legends}

671

672 Fig. 1. Ventral view of the mandible of Tramitichromis sp. and Aulonocara spp. illustrating the 673 canal and superficial neuromasts and mandibular lateral line canals. (A) Ventral view of a 674 juvenile Tramitichromis sp. (standard length $[\mathrm{SL}]=18 \mathrm{~mm})$ and $(\mathrm{B})$ A. stuartgranti $(\mathrm{SL}=16$ $675 \mathrm{~mm})$ fluorescently stained with 4-Di-2-ASP $(63 \mu \mathrm{M}, 5 \mathrm{~min})$ to reveal the hair cells in the sensory 676 strip in superficial neuromasts (lines and clusters [arrows]) and larger canal neuromasts in the 677 mandibular (MD), preopercular (PO), and infraorbital (IO) canals. MicroCT 3-D reconstruction 678 of the mandible [dentary (de) and angulo-articular (aa) bones] of (C) Tramitichromis sp. (SL = $67929 \mathrm{~mm}$ ) showing the bony pores of the MD canal and (D) A. baenschi (SL $=87 \mathrm{~mm})$. 680

Fig. 2. Number of prey strikes (median $\pm \min / \max$ ) on live and dead prey for (A) Tramitichromis

682 (Experiment I) and A. stuartgranti (data from Schwalbe et al., 2012) in light and dark trials, and 683 (B) Tramitichromis (Experiment II, light trials only). LSD, $* * P<0.01, * * * P<0.001$. See text 684 for additional details.

685

686

Fig. 3. Detection distance (mean $\pm \mathrm{SE}$ ) for live and dead prey for (A) Tramitichromis

687 (Experiment I) and A. stuartgranti (data from Schwalbe et al., 2012) in light and dark trials, and 688 (B) Tramitichromis sp. (Experiment II, light trials only). Non-transformed data are illustrated 689 here (which are biologically relevant), but statistics were carried out on log-transformed data, as 690 appropriate. LSD, $* * P<0.01, * * * P<0.001$. See text for additional details. 
693 Fig. 4. Orientation to prey (live and dead combined) at time of detection for (A) Tramitichromis

694 (Experiment I) and A. stuartgranti (data from Schwalbe et al., 2012) light and dark trials and (B)

695 Tramitichromis (Experiment II, light trials only). Bars represent the proportion of the total

696 number of detection events grouped into $20^{\circ}$ intervals. The narrow line represents mean angle.

697 The center of the polar plot (facing $0^{\circ}$ ) represents the location of the midpoint between the eyes.

698 See text for additional details.

699

700 Fig. 5. Frequency of prey detections that occurred during the glide or pause phase of swimming 701 leading to prey strikes in (A) Tramitichromis (Experiment I) and A. stuartgranti (data from 702 Schwalbe et al., 2012) light and dark trials, and (B) Tramtichromis (Experiment II, light trials 703 only). LSD, $* P<0.05, * * * P<0.001$. See text for additional details. 

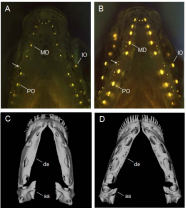

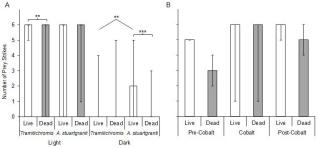
A

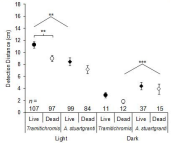

E

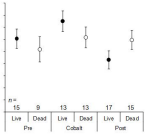


A
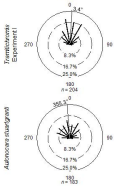

$\theta$

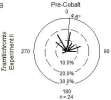

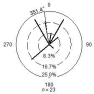
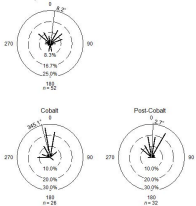

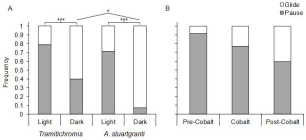

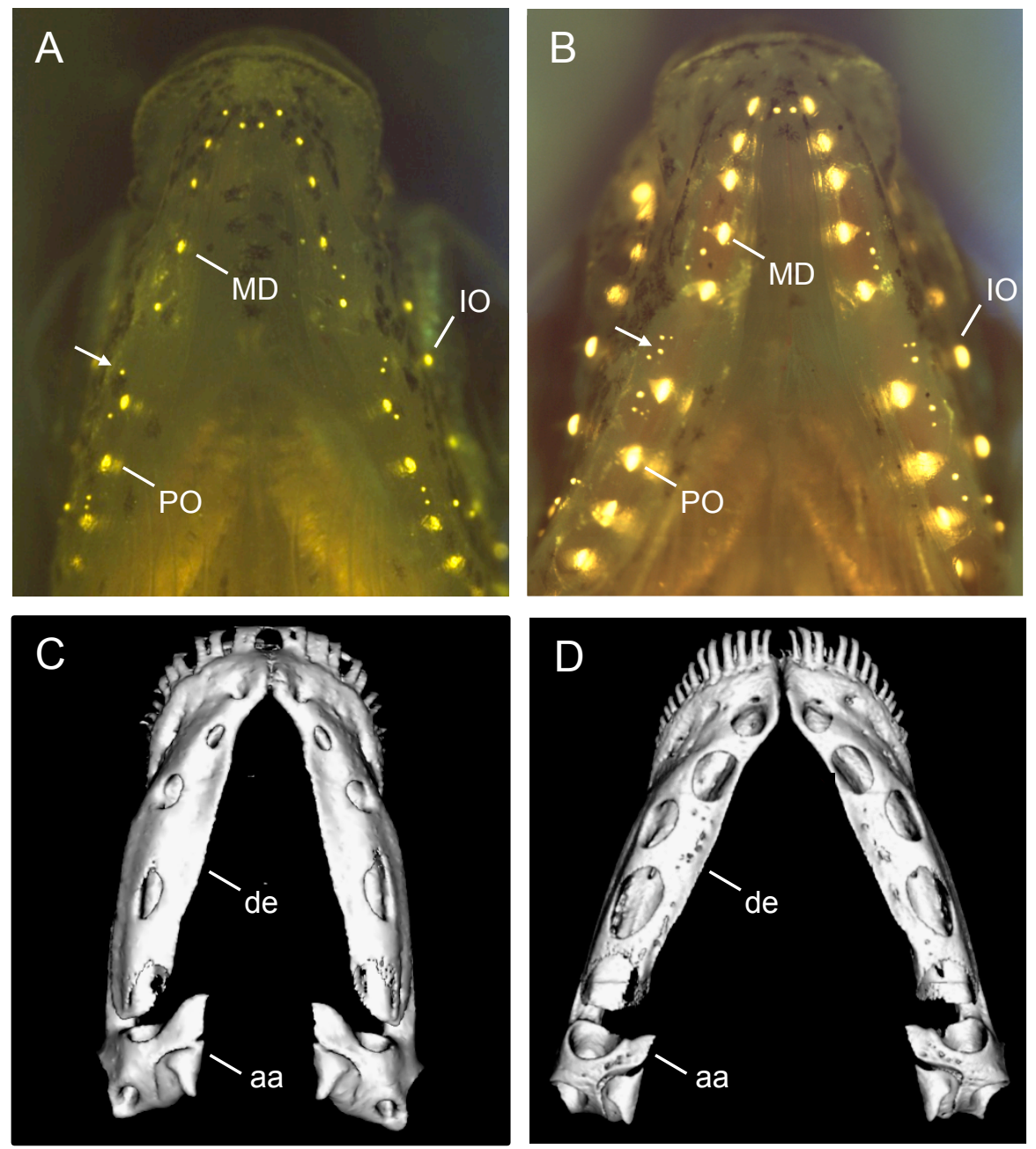

Figure 1. Color 

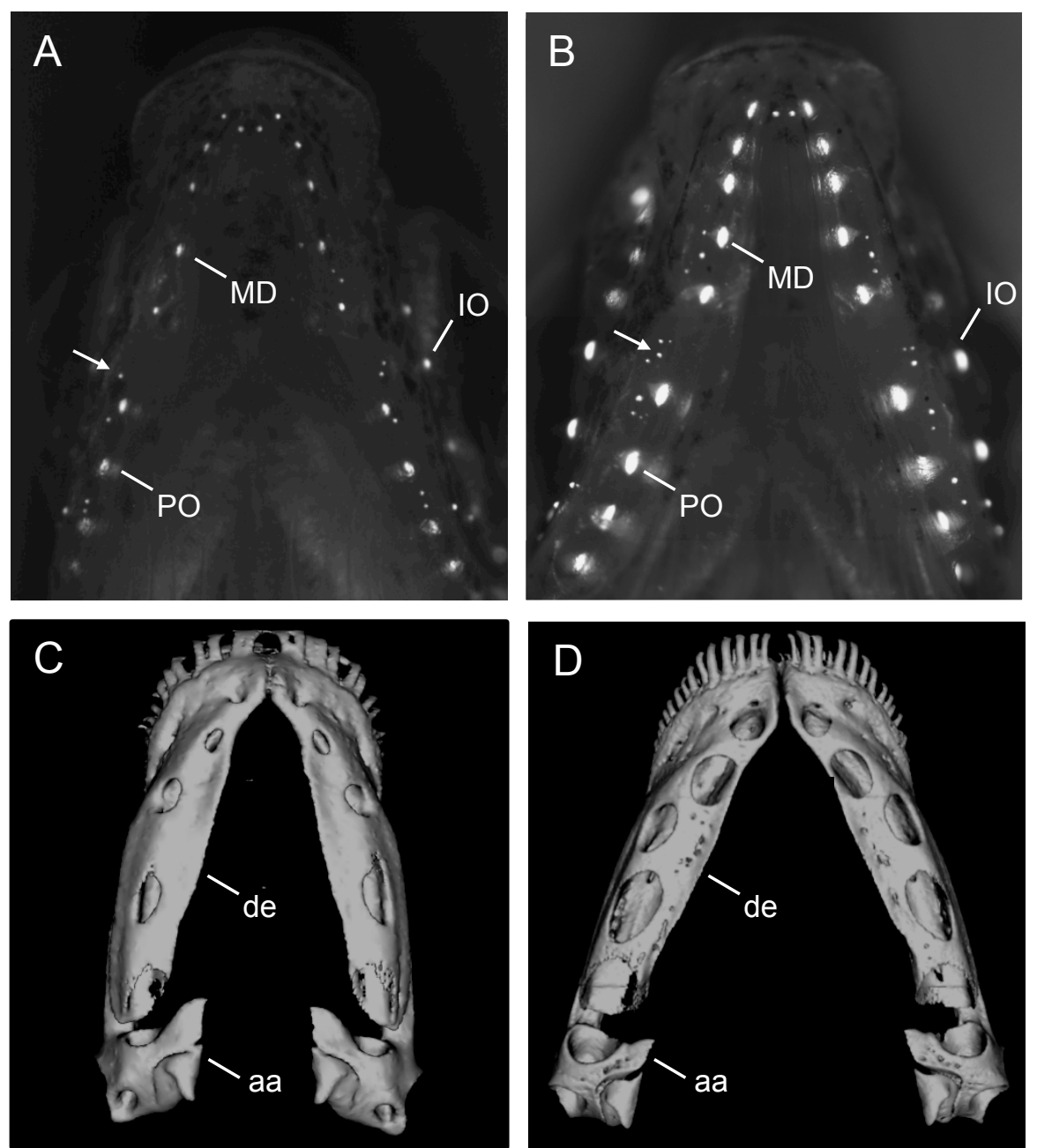

Figure 1. Grayscale 
A

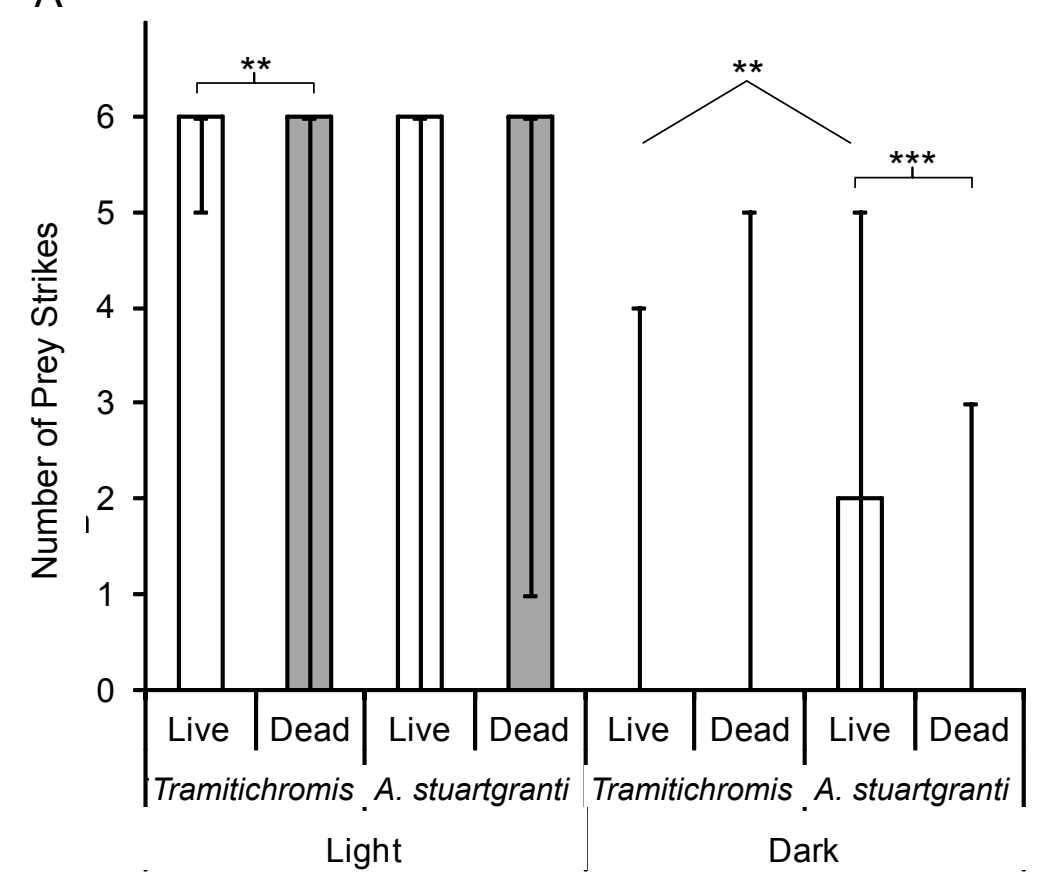

B

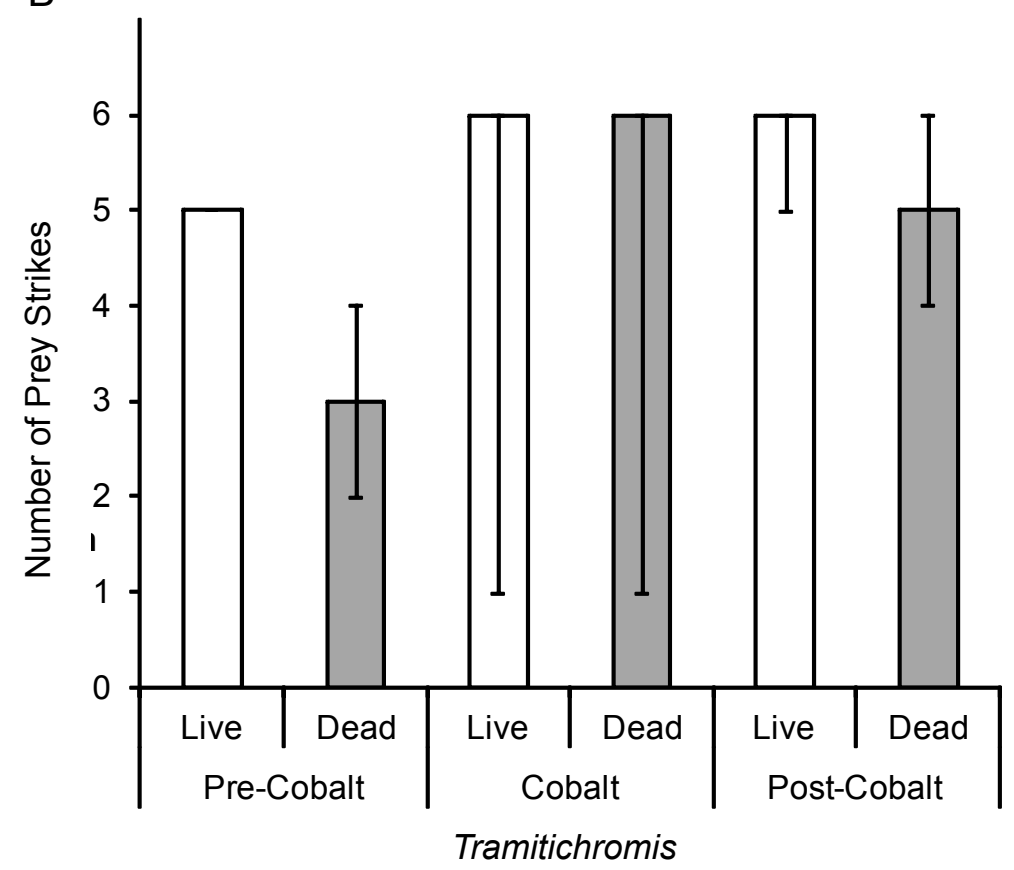

Fig. 2 

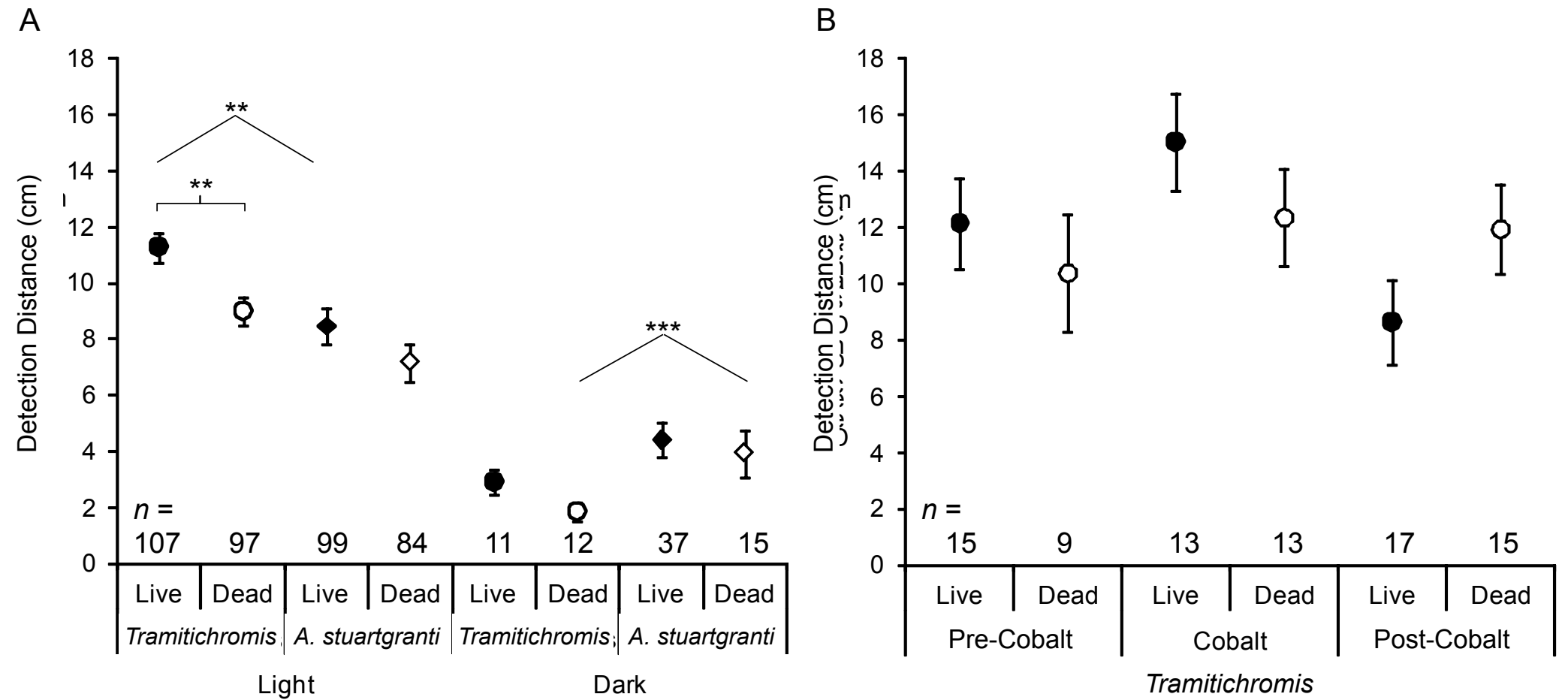

Fig. 3 
A
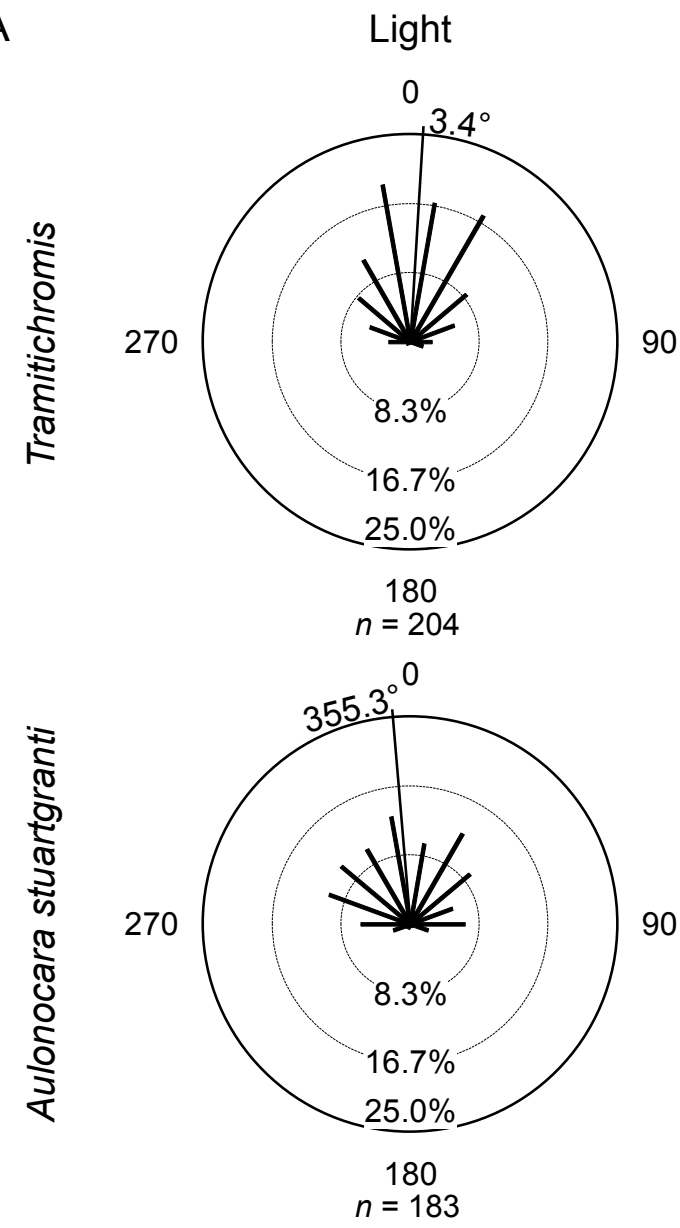

B

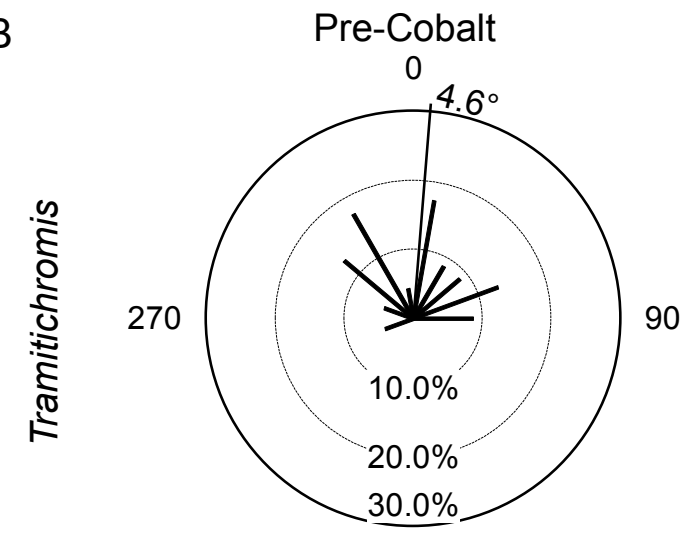

Dark
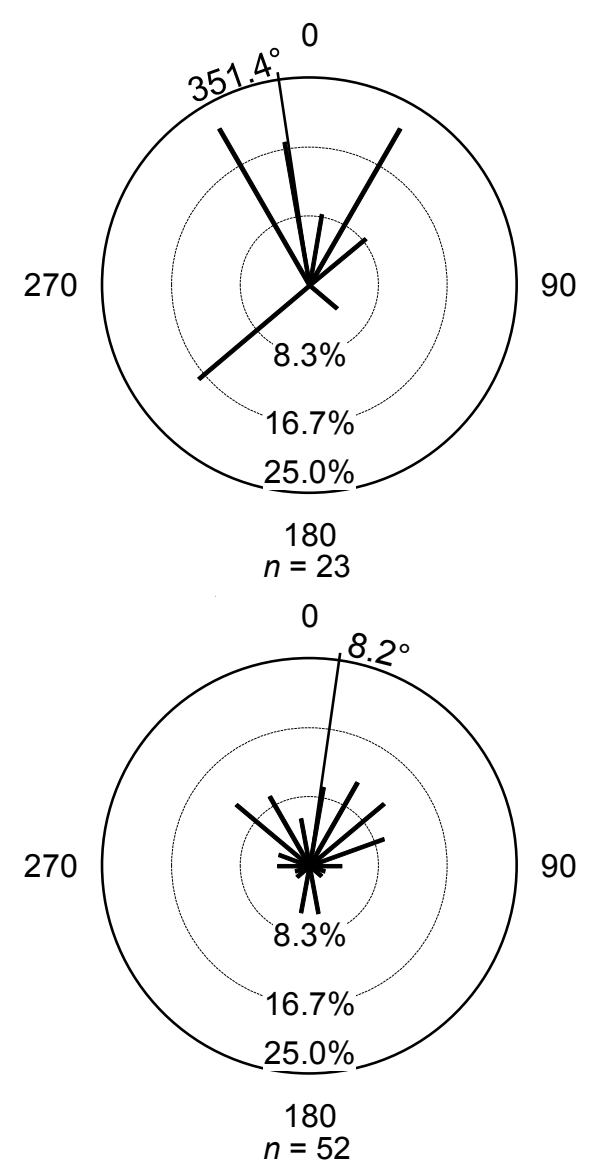

270

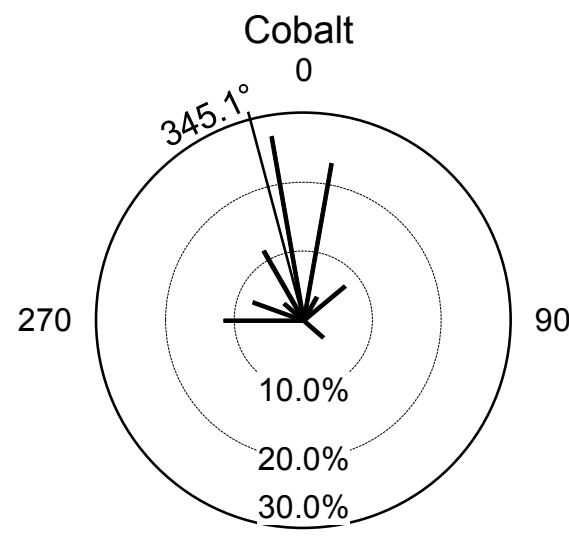

Fig. 4

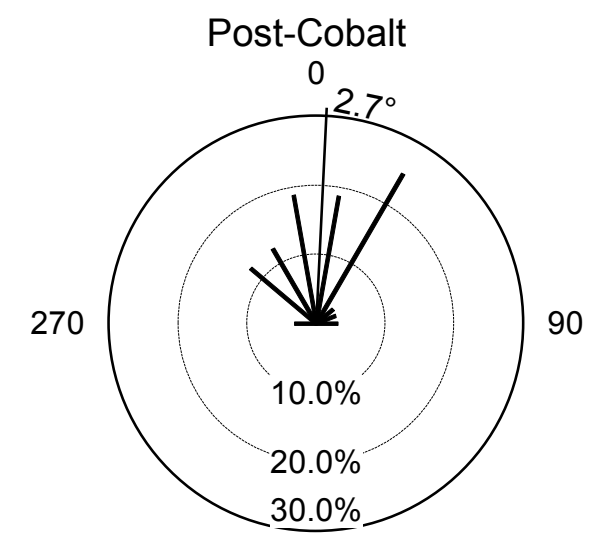



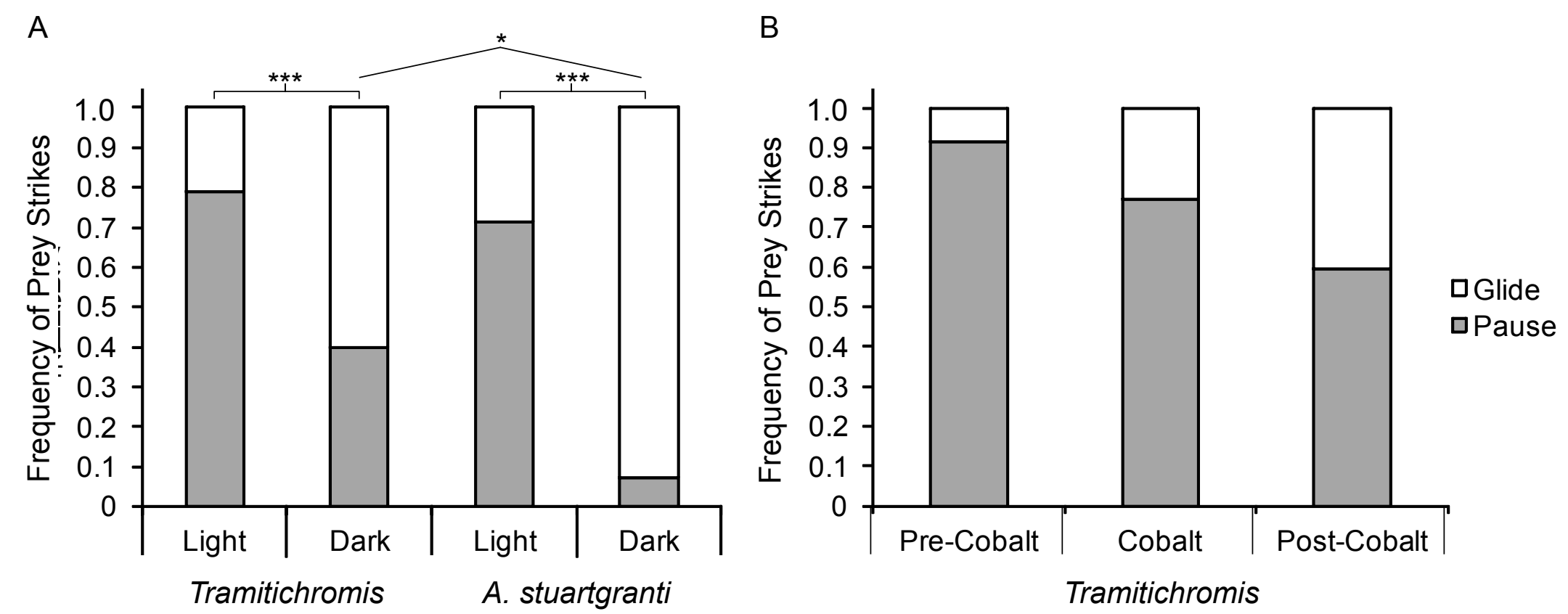

Fig. 5 